\title{
Evidence of increased visceral obesity and reduced physical fitness in healthy insulin-resistant first-degree relatives of type 2 diabetic patients
}

Birgit Nyholm, Michael F Nielsen, Kurt Kristensen ${ }^{1}$, Søren Nielsen, Torben Østergård, Sten B Pedersen ${ }^{1}$, Thomas Christiansen ${ }^{1}$, Bjørn Richelsen ${ }^{1}$, Michael D Jensen ${ }^{2}$ and Ole Schmitz

Department of Medicine M (Endocrinology and Diabetes), Aarhus Kommunehospital, University Hospital of Aarhus and Department of Clinical Pharmacology, University of Aarhus, Aarhus, Denmark, ${ }^{1}$ Department of Medicine C and Department of Radiology, Aarhus Amtssygehus, University Hospital of Aarhus, Aarhus, Denmark and ${ }^{2}$ Mayo Clinic, Rochester, Minnesota, USA

(Correspondence should be addressed to Birgit Nyholm, Department of Medicine M (Endocrinology and Diabetes) Aarhus Kommunehospital, University Hospital of Aarhus, DK-8000 Aarhus C, Denmark; Email: bnyholm@dadlnet.dk)

\begin{abstract}
Objective: First-degree relatives (FDR) of type 2 diabetic patients are often insulin resistant. Visceral obesity is closely linked to both insulin resistance and type 2 diabetes. We therefore hypothesized that the inheritance of an increased tendency to store fat in visceral fat depots may be a characteristic phenotypic feature in FDR contributing to their insulin resistance.

Design and methods: We measured fat distribution in 20 FDR and 14 age-, gender- and body mass index (BMI)-matched controls employing dual energy X-ray absorbtiometry (DEXA)- and computed tomography (CT)-scanning. Insulin-stimulated glucose uptake (ISGU) was determined by a hyperinsulinemic clamp and maximal aerobic work capacity $\left(\mathrm{VO}_{2} \max \right)$ by a bicycle ergometer test. Baseline lipolysis was measured using $\left[{ }^{3} \mathrm{H}\right]$ palmitate. The activity level of the hypothalamic-pituitary-adrenal axis was assessed as the $24 \mathrm{~h}$ urinary $(\mathrm{u})$-cortisol/creatinine ratio.

Results: All subjects had a normal oral glucose tolerance test (OGTT), but FDR were insulin resistant (ISGU: $6.64 \pm 0.48$ vs $9.12 \pm 0.98 \mathrm{mg} / \mathrm{kg} \mathrm{ffm} / \mathrm{min}, P=0.01)$. Despite similar BMI $(25.2 \pm 0.5$ vs $\left.24.8 \pm 0.7 \mathrm{~kg} / \mathrm{m}^{2}, P=0.61\right)$ and overall fat mass $(26.4 \pm 1.6$ vs $24.2 \pm 2.1 \%, P=0.41)$ in FDR vs controls, the amount of visceral adipose tissue was substantially increased $(65.9 \pm 10.0$ vs $\left.40.1 \pm 11.3 \mathrm{~cm}^{2}, P<0.05\right)$ and $\mathrm{VO}_{2} \max$ was reduced $(52.2 \pm 3.1 \mathrm{vs} 63.3 \pm 3.9 \mathrm{ml} / \mathrm{kg} \mathrm{ffm} / \mathrm{min}$, $P<0.05$ ) in FDR. Visceral adiposity was inversely correlated with ISGU (FDR: $r=-0.52$, $P<0.05$; controls: $r=-0.65, P<0.01$ ) and in multiple regression analysis visceral adiposity $(P<0.01), \mathrm{VO}_{2} \max (P<0.001)$ and a family history of type 2 diabetes $(P<0.05)\left(\mathrm{r}^{2}=0.64\right)$ all significantly and independently contributed to the level of ISGU. Baseline palmitate appearance ( $145 \pm 10 \mathrm{vs} 139 \pm 15 \mu \mathrm{mol} / \mathrm{min}, P=0.74)$ and the $24 \mathrm{~h} \mathrm{u}$-cortisol/creatinine ratio $((24.9 \pm 1.3 \mathrm{vs}$ $27.4 \pm 2.0) \cdot 10^{-6}, P=0.28$ ) were both comparable in the two groups.

Conclusion: Healthy but insulin-resistant FDR have enhanced visceral obesity and reduced $\mathrm{VO}_{2}$ max compared with people without a family history of diabetes, despite similar BMI and overall fat mass. Both the visceral adiposity and reduced aerobic fitness are strongly associated with and may contribute to their insulin resistance.
\end{abstract}

European Journal of Endocrinology 150 207-214

\section{Introduction}

Type 2 diabetes has a major hereditary component (1) and first-degree relatives (FDR) of type 2 diabetic patients have a considerably increased risk for development of the disease later in life (2). FDR have been characterized by multiple aberrations in intermediary metabolism and islet cell function even when glucose tolerance is still normal, the most common finding being insulin resistance (3-5), a metabolic feature which has been demonstrated to be a major risk factor for future development of type 2 diabetes (2). However, many aspects behind the diminished insulin sensitivity in FDR are not well elucidated.

Obesity exerts a major impact on insulin sensitivity and is closely associated with type 2 diabetes (6). Genetic factors appear to influence both overall (7) and regional (8) obesity, and the anatomical distribution of adipose tissue appears to be of pivotal importance for the deleterious effects of obesity (9). Thus viscerally 
(or abdominally) obese individuals suffer greater adverse metabolic consequences compared with equally obese individuals with fat primarily stored in subcutaneous fat depots $(6,10)$. In particular, visceral obesity is linked to insulin resistance $(11-13)$, impaired glucose tolerance (IGT) (14) and type 2 diabetes (6, 15, 16). It is therefore tempting to hypothesize that the inheritance of an increased tendency to store fat in visceral fat depots is a common feature in healthy FDR that, in turn, may contribute to their insulin resistance.

Physical work capacity $\left(\mathrm{VO}_{2} \mathrm{max}\right)$ is another cardinal determinant of insulin sensitivity of skeletal muscle (17) and in subcutaneous adipose tissue (18). Recent studies have highlighted the importance of lifestyle intervention, including increased physical activity, for the occurrence of type 2 diabetes (19-21). Low physical fitness per se has been demonstrated to be an independent predictor for the disease (22), and some previous studies have shown reduced $\mathrm{VO}_{2}$ max in healthy FDR $(4,23,24)$. In overt type 2 diabetic patients exercise training increases fitness, improves glycemic control and reduces body weight (25). However, the improvement in glycemic control appears to be related to the loss of central fat rather than to the increased $\mathrm{VO}_{2}$ max. The relationship between insulin sensitivity, overall and visceral obesity and $\mathrm{VO}_{2}$ max in healthy FDR genetically predisposed to type 2 diabetes remains to be elucidated.

Finally, several reports have suggested the presence of a perturbed hypothalamic-pituitary-adrenal (HPA) axis and cortisol excess in the metabolic syndrome including overt type 2 diabetes $(15,26)$. Aspects of this so-called 'hypothalamic arousal' have only been examined rudimentarily in healthy FDR, but a preliminary report (27) has indicated an altered HPA axis in these individuals, which could suggest that cortisol excess contributes to the insulin resistance in FDR.

In the present study, we primarily sought to test the hypothesis that body fat distribution, especially accumulation of visceral adipose tissue, is altered in healthy FDR compared with an age-, gender- and body mass index (BMI)-matched control group without a family history of type 2 diabetes. Secondly, we wanted to examine the relationship between body fat distribution and insulin resistance with respect to glucose and lipid metabolism in these subjects and to assess the potential influence of physical fitness and HPA axis activity on this relationship.

\section{Subjects and methods}

\section{Subjects}

The study included 20 FDR of patients with type 2 diabetes and 14 control subjects without any family history of diabetes. Prior to the study, these two groups were matched with respect to age, gender and BMI. The habitual physical activity level and the waist-to-hip $(\mathrm{W} / \mathrm{H})$ ratio were not used as selection criteria during the recruitment period of the study, although athletes were excluded. FDR were recruited via their type 2 diabetic parent(s) attending the outpatient clinic, Medical Department M, Aarhus Kommunehospital. Within the FDR group five subjects had one parent with type 2 diabetes, ten subjects had one parent and two or more known second-degree relatives with type 2 diabetes, and five subjects had two firstdegree relatives with type 2 diabetes. The control group was recruited among healthy volunteers without any family history of diabetes by advertising. No one in either of the two groups was related. All participants were healthy, of Caucasian origin and were taking no medication. No family history of any other endocrine disorder was present. Additional exclusion criteria were age $>50$ years, BMI $>30 \mathrm{~kg} / \mathrm{m}^{2}$, and alcohol intake on a daily basis. The clinical data of the two groups are shown in Table 1. For a period of 3 days prior to all studies (as outlined below) participants were asked to consume a weight-maintaining diet containing at least $250 \mathrm{~g}$ carbohydrate and to avoid heavy physical exercise. All females were examined in the follicular phase of the menstrual cycle. The protocol was approved by the Ethics Committee in the County of Aarhus and all subjects gave written consent to participate.

\section{Experimental procedure}

Participants were examined on four occasions (I, II, III and IV) separated by approximately $2-4$ weeks. The studies were performed in random order, all following a $12 \mathrm{~h}$ overnight fast.

Table 1 Clinical data of the two groups. Results are expressed as means \pm S.E.M.

\begin{tabular}{|c|c|c|c|}
\hline & $\begin{array}{c}\text { FDR } \\
(n=20)\end{array}$ & $\begin{array}{l}\text { Controls } \\
(n=14)\end{array}$ & $\boldsymbol{P}$ \\
\hline Gender (M/F) & $10 / 10$ & $7 / 7$ & NA \\
\hline Age (years) & $34.8 \pm 2.2$ & $34.6 \pm 2.1$ & 0.94 \\
\hline Smokers (number) & 4 & 3 & 1 \\
\hline BMI $\left(\mathrm{kg} / \mathrm{m}^{2}\right)$ & $25.2 \pm 0.5$ & $24.8 \pm 0.7$ & 0.61 \\
\hline TBW (kg) & $78.2 \pm 2.7$ & $74.9 \pm 3.0$ & 0.5 \\
\hline FFM $(\mathrm{kg})^{*}$ & $53.6 \pm 2.6$ & $52.8 \pm 2.9$ & 0.84 \\
\hline Body fat $(\mathrm{kg})^{*}$ & $20.6 \pm 1.2$ & $18.1 \pm 1.7$ & 0.27 \\
\hline Body fat $(\% \text { of TBW })^{\star}$ & $26.4 \pm 1.6$ & $24.2 \pm 2.1$ & 0.41 \\
\hline W/H ratio & $0.87 \pm 0.01$ & $0.86 \pm 0.02$ & 0.64 \\
\hline ISGU (mg/kg ffm/min) & $6.64 \pm 0.48$ & $9.12 \pm 0.98$ & 0.01 \\
\hline $\mathrm{VO}_{2} \max (\mathrm{ml} / \mathrm{kg} \mathrm{ffm} / \mathrm{min})$ & $52.2 \pm 3.1$ & $63.3 \pm 3.9$ & 0.03 \\
\hline $\mathrm{HbA}_{1 \mathrm{C}}(\%)$ & $5.4 \pm 0.1$ & $5.2 \pm 0.1$ & 0.18 \\
\hline Fasting plasma glucose $(\mathrm{mmol} / \mathrm{l})$ & $5.1 \pm 0.1$ & $4.8 \pm 0.12$ & 0.04 \\
\hline Fasting serum insulin $(\mathrm{pmol} / \mathrm{l})$ & $37.7 \pm 2.6$ & $29.1 \pm 2.3$ & 0.02 \\
\hline Fasting serum FFA $(\mathrm{mmol} / \mathrm{l})$ & $0.51 \pm 0.04$ & $0.46 \pm 0.06$ & 0.44 \\
\hline \multicolumn{4}{|l|}{ Fasting serum lipids } \\
\hline Triglycerides $(\mathrm{mmol} / \mathrm{l})$ & $1.18 \pm 0.09$ & $1.14 \pm c$ & 0.79 \\
\hline Total c & $4.83 \pm 0.23$ & $4.62 \pm 0.17$ & 0.5 \\
\hline HDL-cholesterol (mmol//) & $1.32 \pm 0.09$ & $1.33 \pm 0.11$ & 0.92 \\
\hline
\end{tabular}

* Results from DEXA scanning.

NA, not applicable. 
I: Oral glucose tolerance test and $V O_{2} \max$ All subjects underwent a $3 \mathrm{~h}$ oral glucose tolerance test (OGTT, $75 \mathrm{~g}$ glucose). Blood for determination of plasma glucose and serum insulin was drawn at time $0,15,30,45,60,90,120,150$ and $180 \mathrm{~min}$. Blood for measurements of $\mathrm{HbA}_{1 \mathrm{C}}$, serum free fatty acids (FFA), triglycerides, total cholesterol and high density lipoprotein (HDL)-cholesterol was collected at time zero. After termination of the OGTT, a 6-min submaximal exercise test with continuous monitoring of the heart rate was performed on a bicycle ergometer (Monark Ergometer 829 E, Monark exercise AB, Varberg, Sweden) using a workload of 300 to $1500 \mathrm{kpm} / \mathrm{min}$, depending on age, gender and physical activity as reported by the subject. The mean heart rate during the last $2 \mathrm{~min}$ of work $(>120-130$ beats/min) was used for the calculation of the $\mathrm{VO}_{2}$ max as described by Aastrand (28). In our hands the intraindividual coefficient of variation for this indirect measurement of $\mathrm{VO}_{2}$ max is comparatively small (9.4\%) (29); moreover, the method has been found to correlate well with $\mathrm{VO}_{2}$ max as determined by direct measurements with a variability of $<10 \%$ in both healthy normoglycemic individuals and in subjects with IGT $(24,30)$. Finally, the subjects were asked to evaluate their level of habitual physical activity during work and leisure time using the questionnaire described by Saltin and Grimby (31).

II: Measurements of body composition and HPA axis activity Basal anthropometric measurements were height and total body weight (TBW). BMI was calculated as weight $(\mathrm{kg})$ divided by height (meter) squared. The $\mathrm{W} / \mathrm{H}$ ratio was measured as the smallest circumference around the waist $(\mathrm{cm})$ divided by the largest circumference around the hips $(\mathrm{cm})$. Total body fat (BF $\mathrm{kg}$ ), percentage body fat $(\mathrm{BF} \%)$ and fat free mass (FFM) were evaluated by dual energy X-ray absorptiometry (DEXA) using a QDR-2000 densiometer (Hologic, Waltham, MA, USA). The amount of visceral adipose tissue was assessed by computed tomography (CT) with a Picker PQ 2000 ZAP 100 scanner (Picker, Cleveland, USA) using $130 \mathrm{kV}$ and $200 \mathrm{~mA}$. The areas scanned were $10 \mathrm{~mm}$ thick sectional slices at the levels of vertebrae L2 and L3 respectively, and the amount of visceral adipose tissue was determined automatically in a seeding program with a voxel $Q$ work station. In each individual the degree of visceral adiposity was then expressed as the mean of these two latter results. Finally, subjects collected urine for $24 \mathrm{~h}$ which was analyzed for cortisol and creatinine concentrations.

III: Hyperinsulinemic euglycemic clamp Participants arrived at the Clinical Research Unit at $0730 \mathrm{~h}$. An intravenous cannula was placed in a heated dorsal hand vein for sampling of arterialized blood. The criteria for satisfactory position was oxygen saturation $>90 \%$. Another intravenous cannula was positioned in an antecubital vein for all infusions. After $90 \mathrm{~min}$ of bed resting (time zero) a $150 \mathrm{~min}$ hyperinsulinemic (insulin infusion rate $0.6 \mathrm{mU} / \mathrm{kg} /$ min) euglycemic (plasma glucose $\sim 5 \mathrm{mmol} / \mathrm{l}$ ) clamp protocol was initiated. The intervals between times -30-0 min and 120-150 min were defined as basal and hyperinsulinemic 'steady state' periods respectively. During the study period blood for determination of serum insulin and FFA was collected at time -90, $-30,-15,0,60,120,135$ and $150 \mathrm{~min}$. Plasma glucose was determined every 5 to $10 \mathrm{~min}$ during the clamp. Mean glucose infusion rate between times 120 and $150 \mathrm{~min}$ was defined as 'steady state' insulinstimulated glucose uptake (ISGU). During the clamp, glucose infusion rates have previously been shown essentially to represent insulin-stimulated glucose uptake at the current rate of insulin infusion in nonobese healthy subjects (4) because the endogenous glucose production is suppressed to insignificant values.

IV: FFA turnover FFA (palmitate) turnover was measured by an isotope dilution technique. An intravenous cannula was placed in an antecubital vein for tracer infusion and another cannula was placed in a heated dorsal hand vein for sampling of arterialized blood. After $90 \mathrm{~min}$ of bed resting (time zero) an infusion of $\left[9,10-{ }^{3} \mathrm{H}\right]$ palmitate $(0.3 \mu \mathrm{Ci} / \mathrm{min})$ was started and maintained at a constant rate for $60 \mathrm{~min}$ (time 0-60 min). Blood for determination of total FFA concentrations, palmitate concentrations and specific activity, plasma glucose and serum insulin was obtained at time $-90,0,30,40,50$ and $60 \mathrm{~min}$. The last $30 \mathrm{~min}$ of the palmitate infusion period (time 30-60 min) were considered as 'steady state'. Plasma palmitate concentrations and specific activity were determined by HPLC (32) using $\left[{ }^{2} \mathrm{H}_{31}\right]$ palmitate as internal standard (33).

\section{Analytical methods}

Plasma glucose was measured in duplicate immediately after sampling (Beckman Instruments, Palo Alto, CA, USA). $\mathrm{HbA}_{1 \mathrm{C}}$ was determined by HPLC (reference range $(95 \%$ confidence limits $)=4.4-6.4 \%)$. Serum insulin was determined by ELISA employing a two-site immunoassay (DAKO Diagnostics Ltd, Cambridgeshire, UK). Serum FFA was determined using an enzymatic colorimetric method (Wako Chemicals, Neuss, Germany), whereas serum cholesterol and other measures of lipid metabolism were determined on a COBAS INTEGRA (Roche, Hvidovre, Denmark). Urinary cortisol concentrations were determined by a competitive immunoassay using direct chemiluminescent technology (Chiron Diagnostics Corporation, East Walpole, MA, USA) and urinary creatinine by buffered kinetic Jaffé reaction without deproteinization. 


\section{Statistical analysis}

Data in text, tables and figures are given as means \pm S.E.M. unless otherwise stated. Student's two-tailed $t$-tests for unpaired and paired data were used for comparison of data between and within groups respectively. Because of the well-known close relationship between visceral obesity, insulin resistance and type 2 diabetes, the hypothesis that visceral obesity is increased in healthy FDR compared with the age-, gender- and BMI-matched control group was tested employing Student's one-tailed $t$-test. Relationships between data were analyzed using Pearson product moment correlation analysis, and linear and multiple linear regression analyses. When different measurements of body fat were introduced as independent variables in multiple linear regression analyses these parameters were tested separately and together due to multicollinearity. Rates and proportions were all tested in contingency tables employing Chi-square analysis or Fisher's Exact test. Levels of statistical significance were set at $P<0.05$. Statistical analyses were performed with SigmaStat version 2.03 statistical package (SPSS, Gorinchem, The Netherlands).

\section{Results}

\section{Oral glucose tolerance test}

All subjects had a normal OGTT according to criteria as defined by the Expert Committee on the Diagnosis and Classification of Diabetes, but fasting plasma glucose $(5.1 \pm 0.1$ vs $4.8 \pm 0.1 \mathrm{mmol} / \mathrm{l}, P<0.05)$ as well as the $120-\mathrm{min}$ value $(5.9 \pm 0.2$ vs $4.6 \pm 0.3 \mathrm{mmol} / \mathrm{l}$, $P<0.01)$ were significantly higher in FDR. Similar findings were observed with respect to concentrations of insulin (fasting serum insulin: $37.7 \pm 2.6$ vs $29.1 \pm 2.3 \mathrm{pmol} / \mathrm{l}, \mathrm{P}<0.05 ; 120 \mathrm{~min}$ value: $186 \pm 26$ vs $89 \pm 15 \mathrm{pmol} / \mathrm{l}, \quad P<0.01) . \quad \mathrm{HbA}_{1 \mathrm{c}}$ and fasting serum lipids did not differ significantly between the two groups (Table 1).

\section{Insulin sensitivity and physical activity/capacity}

During the 'steady state' period of the hyperinsulinemic euglycemic clamp circulating insulin $(256 \pm 10$ vs $250 \pm 13 \mathrm{pmol} / \mathrm{l}, P=0.85)$ and glucose $(5.0 \pm 0.0 \mathrm{vs}$ $5.0 \pm 0.0 \mathrm{mmol} / \mathrm{l} ; \quad P=0.93)$ concentrations were almost identical in the two groups. ISGU was, however, significantly reduced in FDR compared with controls $(6.64 \pm 0.48$ vs $9.12 \pm 0.98 \mathrm{mg} / \mathrm{kg} \mathrm{ffm} / \mathrm{min}, P=0.01$, Table 1). No discrepancies during work or during leisure could be established in the habitual physical activity pattern between FDR and controls (median score (range): work: FDR: $2(1-4)$ vs controls: 2 (14); $P=0.98$; leisure: FDR: $2(1-4)$ vs controls: $2(1-4) ; P=0.74)$. However, $\mathrm{VO}_{2}$ max was reduced in FDR $(52.2 \pm 3.1$ vs $63.3 \pm 3.9 \mathrm{ml} / \mathrm{kg} \mathrm{ffm} / \mathrm{min}$, $P<0.05$, Table 1). As expected, there was a close correlation between ISGU and $\mathrm{VO}_{2}$ max in both FDR $(r=0.60, \quad P=0.005)$ and controls $(r=0.68$, $P=0.008)$

\section{Anthropometric variables and assessments of body composition}

Prior to the study, the two groups of FDR and controls were matched in terms of age, gender and BMI. As depicted in Table 1 , the $\mathrm{W} / \mathrm{H}$ ratio was also comparable in the two groups. Results from whole-body DEXA scanning and cross-sectional CT-scanning (L2/L3) are shown in Table 1 and Fig. 1 respectively. FFM was almost identical in FDR and controls (Table 1). Likewise, total and $\mathrm{BF}$ and $\mathrm{BF} \%$ were comparable in the two groups (Table 1). However, as illustrated in Fig. 1 the amounts of visceral adipose tissue were significantly higher in the insulin-resistant FDR compared with controls (CT scan level L2: $68.7 \pm 9.7$ vs $44.5 \pm 12.0 \mathrm{~cm}^{2}, P<0.040$; L3: $63.0 \pm 11.1$ vs $35.8 \pm 10.9 \mathrm{~cm}^{2}, \quad P<0.037$; mean L2/L3: $65.9 \pm 10.0$ vs $\left.40.1 \pm 11.3 \mathrm{~cm}^{2}, \quad P<0.033\right)$. When men and women were analyzed separately, similar results were found although they were barely statistically significant (mean L2/L3 men:100.4 \pm 11.3 vs $66.6 \pm 22.7 \mathrm{~cm}^{2}, P=0.08$; mean L2/L3 women: $31.3 \pm 5.2$ vs $\left.21.2 \pm 3.9 \mathrm{~cm}^{2}, P=0.09\right)$. CT scanning was not performed in two of the 14 controls (one male and one female); however, of note, the anthropometric variables of the remaining 12 controls were comparable to those of the group of FDR (BMI: $24.9 \mathrm{~kg} / \mathrm{m}^{2} ; \mathrm{W} / \mathrm{H}$ : 0.86; overall BF\%: 24.8; $P($ all $)>0.35)$. In both FDR and controls there were significant inverse correlations between ISGU and the degree of visceral obesity (FDR: $r=-0.52, P<0.05$; C: $r=-0.65, P<0.01$; Fig. 2). The two regression lines were comparable with similar slopes $(-0.049 \pm 0.014$ vs $-0.063 \pm 0.021, P=0.46)$ and intercepts $(10.64 \pm 1.15$ vs $11.52 \pm 1.24 \mathrm{mg} / \mathrm{kg}$

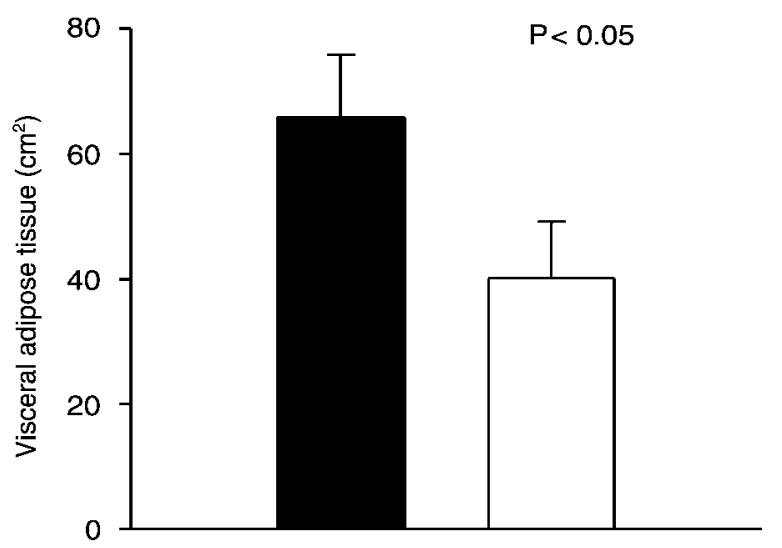

Figure 1 The amount of visceral adipose tissue (cross-sectional CT-scanning over $10 \mathrm{~mm}$ blocks at the level of vertebrae L2/L3) in FDR (solid bar) and controls (open bar) matched in terms of age, gender and BMI. 


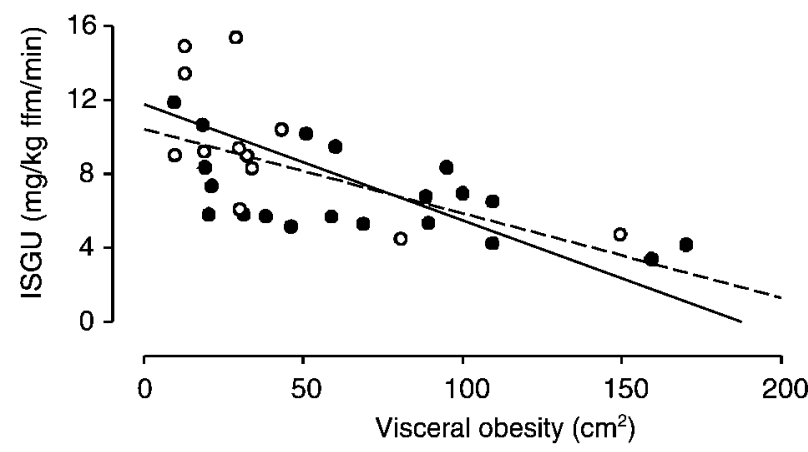

Figure 2 Correlation between insulin-stimulated glucose uptake and visceral obesity in FDR (solid circles: $r=-0.52, P<0.05$ ) and controls (open circles: $r=-0.65, P<0.01$ ). The linear regression is shown as a dotted line for FDR and as a solid line for controls. The two regression lines were comparable with similar slopes and intercepts.

$\mathrm{ffm} / \mathrm{min}, P=0.74)$. There was an inverse correlation between $\mathrm{VO}_{2}$ max and visceral fat area in controls $(r=-0.58, P<0.05)$, whereas this correlation did not reach statistical significance in FDR $(r=-0.39$, $P=0.09$ ).

\section{Estimate of HPA axis activity}

Twenty-four-hour urine $(\mathrm{u})$ cortisol concentrations were comparable in FDR and controls both expressed in absolute terms $(317.0 \pm 24.7$ vs $320.0 \pm 21.4$ $\mathrm{nmol} / \mathrm{l}, P=0.93)$ and as the $24 \mathrm{~h} \mathrm{u}$-cortisol/creatinine ratio $\left((24.9 \pm 1.3\right.$ vs $\left.27.4 \pm 2.0) \cdot 10^{-6}, P=0.28\right)$. The $24 \mathrm{~h} \mathrm{u}$-cortisol/creatinine ratio did not correlate to ISGU or overall $\mathrm{BF} \%$ in either of the two groups. With respect to all correlation analyses similar results were found employing $24 \mathrm{~h}$ u-cortisol concentrations expressed in absolute terms (nmol/l) (data not shown).

\section{FFA concentrations during the clamp}

Fasting concentrations of FFA were almost identical in FDR and controls (Table 1). During the hyperinsulinemic euglycemic clamp (steady state serum insulin: $256 \pm 10$ vs $250 \pm 13 \mathrm{pmol} / \mathrm{l}$; steady state plasma glucose: $5.0 \pm 0.0$ vs $5.0 \pm 0.0 \mathrm{mmol} / \mathrm{l}$, FDR vs controls) circulating FFA concentrations were significantly suppressed in both groups $(P<0.001)$. However, circulating FFA concentrations were significantly greater in FDR during hyperinsulinemia $(0.03 \pm 0.01$ vs $0.01 \pm 0.00 \mathrm{mmol} / \mathrm{l}, \mathrm{P}<0.05)$.

\section{FFA kinetics}

During the $\left[{ }^{3} \mathrm{H}\right]$ palmitate infusion ('steady state' time 30-60 min) average concentrations of total FFA $(0.51 \pm 0.04$ vs $0.46 \pm 0.05 \mathrm{mmol} / \mathrm{l}, \quad P=0.48)$ and palmitate $(135 \pm 11$ vs $128 \pm 10 \mu \mathrm{mol} / \mathrm{l}, \quad P=0.64)$ were comparable in FDR and controls. Likewise, palmitate appearance $(145 \pm 10 \mathrm{vs} 139 \pm 15 \mu \mathrm{mol} / \mathrm{min}$,
$P=0.74$ ) did not differ in the two groups. Of note, however, circulating concentrations of insulin (38.7 \pm 3.0 vs $26.3 \pm 2.9 \mathrm{pmol} / \mathrm{l}, P<0.01)$ were markedly increased in FDR.

\section{Multiple linear regression analysis}

In multiple linear regression analysis with ISGU as the dependent variable $\mathrm{VO}_{2}$ max $(P<0.001)$, visceral obesity $(P<0.01)$ and a family history of type 2 diabetes $(P<0.05)$ all significantly contributed to the level of ISGU $\left(r^{2}=0.64\right)$ whereas gender did not. This model could not be further improved by adding other estimates of body composition, the $24 \mathrm{~h}$ urinary cortisol excretion or fasting insulin and FFA concentrations. If visceral obesity was substituted with percentage BF, the same overall result was reached but the $r^{2}$ value decreased and the $P$ value increased $\left(r^{2}=0.60\right.$, $P(\mathrm{BF} \%)<0.05)$. Details from the best fitted regression equation are shown in Table 2 .

\section{Discussion}

The present study demonstrates that insulin-resistant FDR are characterized by preferential visceral fat accumulation and a reduced $\mathrm{VO}_{2}$ max compared with healthy controls with similar BMI and overall fat mass. In addition, both factors contributed significantly and independently to the level of the insulin resistance in FDR. These data support the hypothesis that healthy FDR exhibit an increased tendency to store fat in visceral fat depots compared with subjects without a family history of diabetes. Although the study design does not allow firm conclusions with respect to causality, it is tempting to speculate that the diminished insulin sensitivity in FDR can be attributed, in part, to an increased amount of visceral adipose tissue and a reduced $\mathrm{VO}_{2}$ max.

Despite the fact that visceral obesity is associated with insulin resistance with respect to glucose metabolism and an increased risk for development of type 2 diabetes $(9,10,15,16)$, quantification of visceral obesity in healthy glucose tolerant FDR has only been carried out sparingly. An upper-body fat distribution has been

Table 2 Multiple linear regression analyses with ISGU $(\mathrm{mg} / \mathrm{kg}$ $\mathrm{ffm} / \mathrm{min}$ ) as dependent variable*

\begin{tabular}{lccc}
\hline $\begin{array}{l}\text { Independent } \\
\text { variable }\end{array}$ & $\begin{array}{c}\text { Parameter } \\
\text { estimate }\end{array}$ & S.E. & $\boldsymbol{P}$ \\
\hline Intercept $(\mathrm{mg} / \mathrm{kg} \mathrm{ffm} / \mathrm{min})$ & 4.013 & 1.508 & $<0.05$ \\
$\mathrm{VO}_{2} \mathrm{max}(\mathrm{ml} / \mathrm{kg} \mathrm{ffm} / \mathrm{min})$ & 0.0743 & 0.016 & $<0.001$ \\
Family history of type 2 diabetes & 1.552 & 0.702 & $<0.05$ \\
$\quad($ yes $=0 / \mathrm{no}=1)$ & & & \\
Visceral obesity $\left(\mathrm{cm}^{2}\right)$ & -0.0219 & 0.0072 & $<0.01$ \\
Gender (male $=0 /$ female $=1)$ & -0.425 & 0.665 & 0.53 \\
\hline
\end{tabular}

* Best fitted regression equation $\left(r^{2}=0.64\right)$

S.E. standard error of parameter estimate. 
found in certain groups of FDR (e.g. 34, 35). However, only the $\mathrm{W} / \mathrm{H}$ ratio was used to assess body composition. In the present study, the CT-verified visceral obesity in FDR (based on two cross-sectional slides) was not associated with an increased $\mathrm{W} / \mathrm{H}$ ratio. Most likely this reflects the fact that the ability of the $\mathrm{W} / \mathrm{H}$ ratio to estimate visceral obesity is limited (36), especially as both our study groups were rather lean. The occurrence of visceral fat accumulation in healthy FDR suggests that this phenotypic characteristic, analogous to insulin resistance (2), is present prior to development of overt type 2 diabetes in these individuals genetically predisposed to type 2 diabetes and thus may be a marker of the early prediabetic state. Of note, the trend towards visceral fat accumulation in FDR was observed irrespective of gender, although subgroup analyses were barely statistically significant, possibly attributable to the reduced number of individuals in each group. Similar observations of increased visceral adiposity was also found to characterize normal weight but 'metabolically obese' women (37) and it was found to precede overt type 2 diabetes in non-diabetic individuals of Japanese American origin (38).

It has recently been suggested that individuals with a family history of type 2 diabetes have a dietary intake which contains more fat and less carbohydrates (39), which may add to the risk of developing type 2 diabetes. Interestingly, an extremely high fat diet given to healthy volunteers for three days was associated with an increase in the intramyocellular lipid content in the tibialis anterior muscle and a concomitant decrease in insulin sensitivity (40). Increased intramyocellular lipid content has also been demonstrated to be related to visceral obesity (41). In the current study all participants consumed at least $250 \mathrm{~g}$ carbohydrate for a period of 3 days prior to each study, but we did not record a detailed dietary history in FDR and controls. Thus we cannot entirely exclude the presence of different eating habits in the two groups. If present, a habitual high fat diet in FDR may partly contribute to the observed differences in insulin sensitivity and visceral adiposity. Further studies are clearly indicated to clarify this field.

Another key finding in the present study was that the $\mathrm{VO}_{2}$ max was significantly reduced in FDR, despite similar physical activity levels during work and leisure compared with controls as evaluated by questionnaire. Reduced physical fitness in FDR has previously been reported by some $(4,23,24)$ but not all $(42,43)$ authors. The discrepancy between these studies may, at least in part, be due to the number of participants and to the recruitment procedure employed. In our study physical fitness was not used for selection of study subjects. Thus both study groups contained individuals with a large range in $\mathrm{VO}_{2}$ max. In contrast, some studies $(42,43)$ have only included subjects with a sedentary lifestyle, thus inducing a possible risk of 'overmatching' i.e. study groups could be matched so closely that tiny differences cannot be detected. Of importance, prospective studies have demonstrated that poor physical fitness is an independent risk factor that predicts development of type 2 diabetes $(22,44)$. The presence of reduced $\mathrm{VO}_{2}$ max in FDR at increased risk for future type 2 diabetes supports these data, and it can be suggested that reduced physical fitness appears to be an important feature of the early prediabetic state. In the present study a questionnaire revealed similar physical activity levels in FDR and controls during work and leisure which may support, but does not prove, a possible genetic background for the reduced physical fitness in FDR. Whether the latter finding can be attributed to genetic or environmental factors remains to be clarified.

Our study also demonstrates that the insulin resistance in FDR is associated with the reduced $\mathrm{VO}_{2}$ max (4). Indeed, $\mathrm{VO}_{2}$ max was the single most important determinant of ISGU independent of both visceral and overall obesity. Thus it is attractive to suggest that the decreased physical fitness in FDR may be an important determinant contributing to their insulin resistance. It is, however, important to underline that a family history of type 2 diabetes independently contributed to the insulin resistance in FDR, i.e. it appears that the early (potentially) prediabetic state per se influences insulinstimulated glucose metabolism. This latter observation is in accordance with data by Perseghin et al. (43) who found that although 6 weeks of aerobic exercise training improved insulin sensitivity in both FDR and controls, FDR remained insulin resistant.

Whereas the positive relationship between $\mathrm{VO}_{2}$ max and insulin-stimulated glucose metabolism has been known for years (17), direct beneficial effects of physical fitness on adipose tissue metabolism is not well characterized. Employing microdialysis, Stallknecht et al. (18) demonstrated that increased fitness was related to improved insulin sensitivity of antilipolysis in subcutaneous abdominal adipose tissue in healthy humans. The possible influence of a family history of type 2 diabetes on the relationship between $\mathrm{VO}_{2}$ max and subcutaneous and visceral adipose tissue lipolysis remains to be determined. Our study showed that $\mathrm{VO}_{2}$ max was inversely correlated to visceral obesity in controls, but not in FDR, which may indicate that the influence of fitness on visceral adipose tissue lipolysis differs in FDR and controls.

Abnormalities in lipid metabolism are well described in type 2 diabetes $(45-47)$, but it is not clear whether these abnormalities are of primarily pathophysiological importance. Consequently, we also sought to assess aspects of adipose tissue metabolism in our healthy but visceral obese and insulin-resistant FDR. Baseline lipolysis, estimated employing $\left[{ }^{3} \mathrm{H}\right]$ palmitate, was not increased in FDR. However, FFA concentrations were threefold greater during hyperinsulinemia, possibly attributable to decreased antilipolytic effects of insulin in visceral adipocytes (48). The normal basal FFA 
concentrations and appearance rates in FDR may be due to compensatory increased insulin concentrations. We have previously observed that upon insulin withdrawal using somatostatin, lipolysis increases to greater levels in upper body obese individuals than in either non-obese controls or lower body obese volunteers (49).

A perturbed HPA axis in FDR resulting in increased circulating cortisol levels could be one important feature contributing to both insulin resistance and visceral obesity. A preliminary report examining HPA axis activity in FDR by means of an oral dexamethasone suppression test, an adrenocorticotropin stimulation test and $24 \mathrm{~h}$ urinary cortisol concentrations has in fact suggested the presence of hypothalamic arousal in these individuals genetically predisposed to type 2 diabetes (27). However, in the present study $24 \mathrm{~h}$ urinary cortisol excretion did not differ between FDR and controls. Moreover, $24 \mathrm{~h}$ urinary cortisol excretion did not contribute to the insulin resistance in FDR. Thus, our data do not support the thesis that cortisol excess is present in healthy FDR.

In conclusion, the present study demonstrates that healthy young non-obese Caucasian FDR are characterized by preferential visceral fat accumulation in both men and women and reduced maximal aerobic fitness when compared with controls without a family history of diabetes despite similar BMI, overall fat mass and physical activity pattern. The increased amounts of visceral fat tissue and the reduced aerobic fitness are both strongly associated with and may contribute to their insulin resistance. Despite visceral obesity in FDR, basal lipolysis appears normal whereas a decreased ability of insulin to suppress lipolysis is seen during hyperinsulinemia. Finally, our data do not support the thesis that cortisol excess is an important determinant of visceral obesity and insulin resistance in the early potentially prediabetic state.

\section{Acknowledgements}

We thank Ms Annette Mengel, Ms Lene Trudsø and Ms Lenette Pedersen for excellent technical assistance. The study was supported by the Danish Diabetic Association, the Danish Research Council, the Institute of Experimental and Clinical Research, University of Aarhus and the Novo-Nordisk Foundation, Copenhagen, Denmark and grant DK40484 from the US Public Health Service.

\section{References}

1 Kahn CR, Vicent D \& Doria A. Genetics of non-insulin-dependent (type-II) diabetes mellitus. Annual Review of Medicine 199647 509-531.

2 Beck Nielsen H \& Groop LC. Metabolic and genetic characterization of prediabetic states: sequence of events leading to non-insulin-dependent diabetes mellitus. Journal of Clinical Investigation $1994941714-1721$.
3 Vaag A, Henriksen JE \& Beck Nielsen H. Decreased insulin activation of glycogen synthase in skeletal muscles in young nonobese Caucasian first-degree relatives of patients with noninsulin-dependent diabetes mellitus. Journal of Clinical Investigation $199289782-788$.

4 Nyholm B, Mengel A, Nielsen S, Skjaerbaek C, Moller N, Alberti KG et al. Insulin resistance in relatives of NIDDM patients: the role of physical fitness and muscle metabolism. Diabetologia $199639813-822$.

5 Perseghin G, Ghosh S, Gerow K \& Shulman GI. Metabolic defects in lean nondiabetic offspring of NIDDM parents: a cross-sectional study. Diabetes $1997 \mathbf{4 6} 1001-1009$.

6 Ohlson LO, Larsson B, Svardsudd K, Welin L, Eriksson H, Wilhelmsen $\mathrm{L}$ et al. The influence of body fat distribution on the incidence of diabetes mellitus: 13.5 years of follow-up of the participants in the study of men born in 1913. Diabetes 1985 34 1055-1058.

7 Bouchard C \& Perusse L. Genetics of obesity. Annual Review of Nutrition $199313337-354$.

8 Bouchard C, Despres JP \& Mauriege P. Genetic and nongenetic determinants of regional fat distribution. Endocrine Reviews $19931472-93$.

9 Montague CT \& O'Rahilly S. The perils of portliness: causes and consequences of visceral adiposity. Diabetes $2000 \quad \mathbf{4 9}$ 883-888.

10 Kissebah AH \& Krakower GR. Regional adiposity and morbidity. Physiological Reviews $1994 \mathbf{7 4} 761-811$.

11 Banerji MA, Chaiken RL, Gordon D, Kral JG \& Lebovitz HE. Does intra-abdominal adipose tissue in black men determine whether NIDDM is insulin-resistant or insulin-sensitive? Diabetes 1995 $44141-146$.

12 Albu JB, Curi M, Shur M, Murphy L, Matthews DE \& Pi-Sunyer FX. Systemic resistance to the antilipolytic effect of insulin in black and white women with visceral obesity. American Journal of Physiology 1999277 E551-E560.

13 Pedersen SB, Borglum JD, Schmitz O, Bak JF, Sorensen NS \& Richelsen B. Abdominal obesity is associated with insulin resistance and reduced glycogen synthetase activity in skeletal muscle. Metabolism $1993 \mathbf{4 2} 998-1005$.

14 Pascot A, Despres JP, Lemieux I, Bergeron J, Nadeau A, Prud'homme D et al. Contribution of visceral obesity to the deterioration of the metabolic risk profile in men with impaired glucose tolerance. Diabetologia 200043 1126-1135.

15 Bjorntorp P \& Rosmond R. Visceral obesity and diabetes. Drugs 199958 (Suppl 1) 13-18.

16 Wajchenberg BL. Subcutaneous and visceral adipose tissue: their relation to the metabolic syndrome. Endocrine Reviews 200021 697-738.

17 Koivisto VA, Yki Jarvinen H \& DeFronzo RA. Physical training and insulin sensitivity. Diabetes: Metabolism Reviews 19861 445-481.

18 Stallknecht B, Larsen JJ, Mikines KJ, Simonsen L, Bulow J \& Galbo H. Effect of training on insulin sensitivity of glucose uptake and lipolysis in human adipose tissue. American Journal of Physiology 2000279 E376-E385.

19 Pan XR, Li GW, Hu YH, Wang JX, Yang WY, An ZX et al. Effects of diet and exercise in preventing NIDDM in people with impaired glucose tolerance. The Da Qing IGT and Diabetes Study. Diabetes Care 199720 537-544.

20 Tuomilehto J, Lindstrom J, Eriksson JG, Valle TT, Hamalainen H, Ilanne-Parikka $\mathrm{P}$ et al. Prevention of type 2 diabetes mellitus by changes in lifestyle among subjects with impaired glucose tolerance. New England Journal of Medicine 2001 344 1343-1350.

21 Diabetes Prevention Program Research Group. Reduction in the incidence of type 2 diabetes with lifestyle intervention or metformin. New England Journal of Medicine 2002346 393-403.

22 Eriksson KF \& Lindgarde F. Poor physical fitness, and impaired early insulin response but late hyperinsulinaemia, as predictors of NIDDM in middle-aged Swedish men. Diabetologia 199639 $573-579$. 
23 Berntorp K \& Lindgarde F. Impaired physical fitness and insulin secretion in normoglycaemic subjects with familial aggregation of type 2 diabetes mellitus. Diabetes Research 1985 2 151-156.

24 Berntorp K, Eriksson KF \& Lindgarde F. The importance of diabetes heredity in lean subjects on insulin secretion, blood lipids and oxygen uptake in the pathogenesis of glucose intolerance. Diabetes Research $19863231-236$.

25 Walker KZ, Piers LS, Putt RS, Jones JA \& O’Dea K. Effects of regular walking on cardiovascular risk factors and body composition in normoglycemic women and women with type 2 diabetes. Diabetes Care 199922 555-561.

26 Bjorntorp P, Holm G \& Rosmond R. Hypothalamic arousal, insulin resistance and type 2 diabetes mellitus. Diabetic Medicine 199916 $373-383$.

27 Lindmark S, Olsson T, Tufvesson M \& Eriksson JW. Cortisol axis is altered in healthy relatives of type 2 diabetic parents. Diabetes 199948 (Suppl 1) A201.

28 Aastrand I. Aerobic work performance in men and women with special references to age. Acta Physiologica Scandinavia 196049 (Suppl 169) 1-92.

29 Gravholt $\mathrm{CH}$, Holck P, Nyholm B, Christiansen E, Erlandsen M \& Schmitz O. No seasonal variation of insulin sensitivity and glucose effectiveness in men. Metabolism $20004932-38$.

30 Lindgarde F \& Saltin B. Daily physical activity, work capacity and glucose tolerance in lean and obese normoglycaemic middle-aged men. Diabetologia 198120 134-138.

31 Saltin B \& Grimby G. Physiological analysis of middle-aged and old former athletes. Comparison with still active athletes of the same ages. Circulation $1968381104-1115$.

32 Miles JM, Ellman MG, McClean KL \& Jensen MD. Validation of a new method for determination of free fatty acid turnover. American Journal of Physiology 1987252 E431-E438.

33 Jensen MD, Rogers PJ, Ellman MG \& Miles JM. Choice of infusionsampling mode for tracer studies of free fatty acid metabolism. American Journal of Physiology 1988254 E562-E565.

34 Vaag A, Henriksen JE, Madsbad S, Holm N \& Beck Nielsen H. Insulin secretion, insulin action, and hepatic glucose production in identical twins discordant for non-insulin-dependent diabetes mellitus. Journal of Clinical Investigation 199595 690-698.

35 Groop L, Forsblom C, Lehtovirta M, Tuomi T, Karanko S, Nissen M et al. Metabolic consequences of a family history of NIDDM (the Botnia study): evidence for sex-specific parental effects. Diabetes $1996451585-1593$.

36 Despres JP, Prud'homme D, Pouliot MC, Tremblay A \& Bouchard C. Estimation of deep abdominal adipose-tissue accumulation from simple anthropometric measurements in men. American Journal of Clinical Nutrition $19915 \mathbf{5 4} 41-477$.

37 Dvorak RV, DeNino WF, Ades PA \& Poehlman ET. Phenotypic characteristics associated with insulin resistance in metabolically obese but normal-weight young women. Diabetes $1999 \mathbf{4 8}$ 2210-2214.

38 Boyko EJ, Fujimoto WY, Leonetti DL \& Newell-Morris L. Visceral adiposity and risk of type 2 diabetes: a prospective study among Japanese Americans. Diabetes Care 200023 465-471.

39 Adamson AJ, Foster E, Butler TJ, Bennet S \& Walker M. Non-diabetic relatives of type 2 diabetic families: dietary intake contributes to the increased risk of diabetes. Diabetic Medicine 200118 984-990.

40 Bachmann OP, Dahl DB, Brechtel K, Machann J, Haap M, Maier T et al. Effects of intravenous and dietary lipid challenge on intramyocellular lipid content and the relation with insulin sensitivity in humans. Diabetes $2001502579-2584$.

41 Forouhi NG, Jenkinson G, Thomas EL, Mullick S, Mierisova S, Bhonsle U et al. Relation of triglyceride stores in skeletal muscle cells to central obesity and insulin sensitivity in European and South Asian men. Diabetologia 199942 932-935.

42 Laws A, Stefanick ML \& Reaven GM. Insulin resistance and hypertriglyceridemia in nondiabetic relatives of patients with non-insulin-dependent diabetes mellitus. Journal of Clinical Endocrinology and Metabolism $198969343-347$.

43 Perseghin G, Price TB, Petersen KF, Roden M, Cline GW, Gerow K et al. Increased glucose transport-phosphorylation and muscle glycogen synthesis after exercise training in insulin-resistant subjects. New England Journal of Medicine 1996335 $1357-1362$.

44 Wei M, Gibbons LW, Mitchell TL, Kampert JB, Lee CD \& Blair SN. The association between cardiorespiratory fitness and impaired fasting glucose and type 2 diabetes in men. Annals of Internal Medicine 1999130 89-96.

45 Reaven GM, Hollenbeck C, Jeng CY, Wu MS \& Chen YD. Measurement of plasma glucose, free fatty acid, lactate, and insulin for $24 \mathrm{~h}$ in patients with NIDDM. Diabetes $1988 \quad 37$ $1020-1024$.

46 Vaag A, Alford F, Henriksen FL, Christopher M \& Beck Nielsen H. Multiple defects of both hepatic and peripheral intracellular glucose processing contribute to the hyperglycaemia of NIDDM. Diabetologia 199538 326-336.

47 Reaven GM. Role of insulin resistance in human disease. Diabetes $1988371595-1607$.

48 Richelsen B, Pedersen SB, Moller-Pedersen T \& Bak JF. Regional differences in triglyceride breakdown in human adipose tissue: effects of catecholamines, insulin, and prostaglandin E2. Metabolism 199140 990-996.

49 Jensen MD. Regulation of forearm lipolysis in different types of obesity: in vivo evidence for adipocyte heterogeneity. Journal of Clinical Investigation 199187 187-193.

Received 28 July 2003

Accepted 15 October 2003 